Article

\title{
Cultural Education: Panacea or Amplifier of Existing Inequalities in Political Engagement?
}

\author{
Lea Fobel ${ }^{1}$ and Nina Kolleck ${ }^{1,2, *}$ \\ ${ }^{1}$ Political Education and Education Systems, Leipzig University, Germany; E-Mails: lea.fobel@uni-leipzig.de (L.F.), \\ nina.kolleck@uni-leipzig.de (N.K.) \\ ${ }^{2}$ Educational Research and Social Systems, Freie Universität Berlin, Germany \\ * Corresponding author
}

Submitted: 30 March 2021 | Accepted: 25 May 2021 | Published: 16 September 2021

\begin{abstract}
Cultural education has recently been particularly emphasized as key for the promotion of equal opportunities, social cohesion and political engagement. While the relationship between political engagement and formal education has been extensively discussed, little research has been conducted on non-formal types of education, such as non-formal cultural education (NCE) in particular. However, the share of NCE programmes is becoming increasingly important as more and more formal institutions are reducing their cultural education programmes. This article examines, firstly, whether NCE actually promotes political engagement and, secondly, who effectively participates in NCE programmes. Using data from the eighth wave (2016-2017) of the German National Educational Panel Study, we implement a mediation analysis within ordered logistic regression models to disentangle the mechanisms at play. Our results indicate that NCE exerts a small but significant effect on political engagement directly and indirectly via political discussions and political interest. However, participation in NCE is strongly influenced by social strata. The advantages of NCE are therefore not evenly distributed across the German population.
\end{abstract}

\section{Keywords}

cultural education; equal opportunities; mediation analysis; political engagement

\section{Issue}

This article is part of the issue "Education, Politics, Inequalities: Current Dynamics and Perspectives" edited by Kenneth Horvath (University of Lucerne, Switzerland) and Regula Julia Leemann (University of Teacher Education FHNW, Switzerland / University of Basel, Switzerland).

(C) 2021 by the authors; licensee Cogitatio (Lisbon, Portugal). This article is licensed under a Creative Commons Attribution 4.0 International License (CC BY).

\section{Introduction}

Political discontent (Holtmann et al., 2019), extremism, radicalisation tendencies (Holtmann, 2020), and social polarisation (Brähler et al., 2016; Müller, 2019; Rehberg, 2006) shape public debates in many European countries and demand innovative strategies that sustainably promote social cohesion and democratic structures. Access to and participation in educational programmes have been an integral part of discussions on political engagement for several years. Cultural and arts education in particular (hereafter referred to as cultural education) has received a lot of attention recently and has often been proclaimed as a panacea for some of these profound social challenges (Jessop, 2017). Besides knowledge of the arts themselves, cultural education aims to promote the maturity of children, young people and adults, critical thinking on social processes (Dumitru, 2019; Lampert, 2006), personality development and to provide spaces to challenge social traditions and values (Fietz, 2009). Cultural education might therefore offer the possibility of equipping individuals of all ages with many of the necessary skills to shape society and sustainably participate in democratic processes. Most of 
these findings come from studies on formal cultural education provision within school curricula (Dumitru, 2019). In recent years, however, a decline of arts subjects in the German school curriculum can be observed. Although non-formal programmes previously provided a substantial part of the cultural education structure, the proportion of non-formal programmes has been significantly increased to compensate for the decline in formal programmes in Germany (Bock-Famulla et al., 2015; Liebau, 2018; Rat für Kulturelle Bildung e.V., 2015). Contrary to participation in formal education, participation in non-formal education is not regulated by law and therefore subject to amplified mechanisms of selection. Whether and in which programmes people participate is not simply a question of individual interests. Not only are personal interests equally determined by social structure, they are also complemented by other important factors of participation, such as the economic and time resources of families. Since participation in non-formal education programmes is dependent on several structural prerequisites and an increasing share of cultural education programmes is taking place in non-formal settings, the question arises, especially against the background of participation in democratic processes, to what extent and in which ways patterns of participation in non-formal cultural education (NCE) are influenced by social strata. If there are distinct mechanisms of inclusion and exclusion that favour or disadvantage certain people, not everyone benefits equally from the opportunities that NCE programmes offer. Therefore, we first aim to examine the extent to which NCE influences political engagement. Afterwards, we investigate patterns of participation in NCE by individuals' socioeconomic and regional backgrounds (Blossfeld \& Shavit, 2015; Bourdieu, 1984). This approach has the advantage of producing a robust, comparable and tangible result and thus providing empirical support for important discussions on the issue. Research on cultural education is both very broad and very traditional in its perspectives. A study that takes this into account and combines the different aspects is thus an important addition to the field.

\section{Conceptual Framework: Cultural Education and Political Engagement}

Cultural education has become increasingly politicised in both scientific and political discussions. Many practitioners, politicians and scientists have highlighted the distinctive effects cultural education seems to have on social participation and cohesion as well as on important soft skills (Fietz, 2009; Lampert, 2006). Based on past research, there is a relative consensus in academia that education as a whole has a positive impact on political engagement (Desjardins \& Schuller, 2006). More than other disciplines in the education sector, cultural education can provide a unique space to make different social and political models conceivable and to test them without consequences. Art and culture often make it possible to change one's perspective on certain circumstances or to take on and try out new roles (Bockhorst, 2008; Fuchs, 2008). A theoretical point of departure for these considerations is provided by Theodor Adorno with his understanding of culture and teaching. Adorno is known as one of the most relevant representatives of the Frankfurt School and as a harsh critic of modernity. An important interpretation of his work in the context of cultural education was published in 2017 by Sharon Jessop. According to Jessop, Adorno understood culture as a questioning of the status quo and "resist[ing] heteronomous ways of thinking" (Jessop, 2017, p. 420). He would describe the plurality of cultures" as a site where resistance and critical thinking can happen in "a context of rich experience of incorrigible plurality" (Jessop, 2017, p. 420). The "plurality of cultures" can be understood not only as a plurality of cultures amongst the participants but a plurality of perspectives through engagement with cultural objects and activities. To him, "having culture" would be indicated by "demonstrat[ing] an interest in making connections and comparisons, in questioning what happens to be the case, and being personally entangled in the immanent criticality of the situation" (Jessop, 2017, p. 418). Criticism and culture would therefore be, ideally, inseparably united and education should always lean towards self-reflection. Jessop concludes that following Adorno, mass cultural education would be "the most powerful institutional tool in shaping and changing how people think and behave" (Jessop, 2017, p. 417). However, Adorno did not precisely specify how these skills could be taught or learned.

Moreover, according to Adorno, pure, critical culture has to be "disinterested" and therefore autonomous of the market. A disillusioning result of Adorno's is that only intellectual, privately wealthy people can create critical, autonomous culture, as they are the ones truly disconnected from the market (Gartman, 2012, pp. 48-49). Another important scholar in the field, Pierre Bourdieu, challenged this assumption in his later years and formulated another prerequisite for the production of critical, autonomous culture: diversity (Bourdieu, 2000, p. 157). Pierre Bourdieu (1984) argued in his work on social class, capital and taste that participation in cultural activities is essentially determined by social class. According to him, members of higher social classes are more likely to consume highbrow cultural programmes, while members of lower classes are more likely to engage in popular cultural activities. At the same time, social class enables different perspectives on the benefits of certain activities and promotes or hinders participation in these activities to a greater or lesser extent (Boudon, 1974; Bourdieu, 1981, 2000). Although Bourdieu did not rank highbrow culture and popular culture at this point, he moved towards Adorno's position on critical, autonomous culture in his later years, declaring that disinterested, autonomous culture is a "universal possibility" (Bourdieu, 1998, p. 135). Though autonomy of art is now a common feature of both theories, Bourdieu 
criticized the exclusivity of pure cultural production to intellectuals by claiming that only members of lower social classes, due to the sensitivity provided by their habitus, can address the economic foundation of their works (Bourdieu, 2000, p. 157; Gartman, 2012, p. 70). To achieve a more diverse production of critical culture, according to Bourdieu, more state funding is needed, since otherwise only a very exclusive group of people would have access to autonomous art (Bourdieu \& Haacke, 1995).

In this article, we do not aim to discuss both theories in detail. Rather, we use both theories to compensate for the shortcomings of either (Gartman, 2012, p. 66). In the past, empirical research on cultural education has mostly relied solely on ideas from Bourdieu. We would like to show that such research, referring to Bourdieu alone, remains entrenched in the cultural dichotomy of highbrow and lowbrow activities and reproduces previously known patterns. The combination of Adorno's and Bourdieu's arguments that we propose in this article not only offers opportunities for diversification to research on arts education but also allows for the adoption of different, complementary perspectives and thereby the openness to discovering new, previously undiscovered aspects of cultural education.

\subsection{Central Concepts and (Policy) Background}

In the German formal education system, schooling is compulsory from 9 to 13 years. After ninth grade, children and young people have the opportunity to complete various types of education. The school system in Germany is organized on a federal level, i.e., different rules exist depending on the federal state and municipality, and in some cases the structures vary between the individual schools or school types. The school systems of the individual federal states differ greatly, but each follows a form of segregation. In general, students attend primary school together for the first four to six years and then transfer to a secondary school. The choice of secondary school is-with a few exceptions-made based on school performance in primary school. Depending on the federal state and the type of school, children have the option of earning the Abitur (A-Level or high school diploma in upper secondary education) after 12 or 13 years and thus the university entrance qualification. Not every secondary school (e.g., lower and intermediate secondary schools) in every state offers the option of earning an A-Level degree at the end of high school (Organisation for Economic Co-operation and Development, 2011). Whether or not pupils continue their education in tertiary institutions is therefore highly dependent on their secondary schooling, as only individuals from upper secondary education receive a general university entrance qualification (see, e.g., von Below et al., 2013). However, an increasing number of vocational training programmes favour or even require pupils with degrees from upper secondary institutions as espe- cially popular programmes have larger pools of applicants to choose from. Overall, the school-leaving qualification in Germany is of great importance for the further education of individuals and attractive occupational pathways (von Below et al., 2013).

Cultural education itself can be part of the formal education system by discussing literature in German classes or attending music classes. In voluntary study groups, many schools offer courses outside of compulsory classes to provide additional educational opportunities for their pupils, such as drama or chess clubs. In addition to these classes and clubs within formal settings, there are also many non-formal programmes of cultural education outside of formal educational institutions, such as music schools, education centres, cultural associations or choirs. However, the concept "cultural education" is not uniformly defined in Germany (Kolleck \& Büdel, 2020). To avoid falling back into the dichotomy of high- and lowbrow types of NCE, we utilise a very broad definition of cultural education including socio-cultural as well as artistic-aesthetic aspects of non-formal education. In this sense, cultural education encompasses any learning of, with or through artistic and cultural objects or activities (Kolleck \& Büdel, 2020). According to the open definition chosen in this study, NCE would be defined as all educational activities that do not lead to a formal educational qualification but are institutionalised, such as theatre or carnival clubs or extracurricular cultural education such as music or pottery classes. Activities that are carried out alone or with friends outside of institutionalised associations, such as private band activities, reading or other interpersonal but informal knowledge exchange are not included in this article. Depending on the type of cultural education programme attended, different stimuli could affect the individual. Cultural education supports the development of an individual's personality by recognising and developing their strengths and interests. In addition, individuals can learn to work together, be responsible and exert influence. It is also not uncommon, especially in cultural education, to change perspectives, for example when dealing with texts of any kind or testing out new ideas in the context of singing, reading, making music, carnival clubs, playing theatre or crafting. In addition, there is the possibility of practising new forms of cultural expression in the digital as well as the analogue world, thereby experiencing and tolerating diversity. At least in theory, cultural education thus provides several impulses that can promote critical and creative engagement with social challenges (Bockhorst, 2008; Fuchs, 2008).

In this context and following Adorno and Ashton (2007), we use a broad definition of "political engagement." We assume that political engagement takes place as soon as a critical examination of a certain topic has been realised since a thought of resistance has already emerged (Adorno \& Ashton, 2007). More specifically, we understand all activities as political engagement that deal critically with current social phenomena or conflicts 
and would theoretically be willing to represent this critical attitude to the public. The definition of political engagement pursued in this article thus differs from other concepts concerning the assumption that activities of political engagement have to demonstrate a (direct) influence on politics (van Deth, 2015).

\subsection{Current Research and Hypotheses}

Mass education seems to be an ideal prerequisite to promote critical thinking. Formal school settings, however, rarely allow for intensive and open discussions among students. In addition, most school curricula and syllabi provide relatively little time for cultural education (Blossfeld et al., 2015; Maaz et al., 2010). Additionally, formal education is per definition instrumental as it is targeted at achieving formal degrees of education. In contrast, research suggests that interactive learning methods such as peer discussions are key to fostering critical thinking and civic skills (Guiller et al., 2008; Oros, 2007; Szabo \& Schwartz, 2011). Especially in heterogeneous groups, listening and responding to different and sometimes contradictory arguments offers opportunities to promote democratic soft skills (Oros, 2007, p. 309). Non-formal education does not aim at commonly accepted educational certificates. Hence, non-formal voluntary settings could provide an environment in which the "plurality of cultures" can be discussed extensively and outside of rational considerations. Against this background, we develop our first hypotheses:

$\mathrm{H} 1 \mathrm{a}$ : If individuals participate in NCE, they are more likely to be involved in political discussions.

$\mathrm{H} 1 \mathrm{~b}$ : If individuals participate in NCE, they are more likely to be politically interested.

Though many researchers investigated participatory patterns in cultural activities, most research was done on formal cultural education or visits to cultural institutions such as museums or cinemas. A popular context for NCE, however, is association membership. Numerous studies have shown that active participation in voluntary organisations is strongly associated with a functioning democracy. Scholars as early as de Tocqueville (1969) found the relationship between voluntary associations and democratic behaviour evident and provided the basis for a fundamental branch of democracy research (Almond \& Verba, 2015; Verba et al., 1995). Voluntary associations in general, but also in the context of cultural education, often provide mechanisms of socialisation, as they introduce individuals implicitly and explicitly to political issues (van Deth, 2000). Depending on the association, participants learn civic and organisational skills to varying degrees (Baggetta, 2009), as well as how to work in heterogeneous groups and networks (Putnam, 2001). Through these relatively low-threshold associations, the individual may become attentive to larger social and political issues (Quintelier, 2013) and develop or consolidate their democratic values (Hooghe, 2003). These experiences could then in turn be translated into active action, as one's creative possibilities and democratic responsibilities are strengthened. Thus, we pose our second hypothesis:

$\mathrm{H} 2$ : If individuals participate in NCE, they are more likely to potentially take part in political protest.

However, participation in such organisations is biased and not just subject to the individual's motivation to take part, but also to their opportunities. Critics argue that underlying resources and personality traits such as economic resources, social skills or proactive behaviour, stimulate individuals differently regarding civic and political activities and promote mechanisms of self-selection (Grotlüschen, 2016; Hooghe, 2003; van der Meer \& van Ingen, 2009). Furthermore, resources-or a lack thereof-can prevent individuals from participating when they cannot meet the minimum financial and time requirements or may not even know about cultural education programmes. Especially in the context of cultural education, participation can be expensive, as musical instruments and artistic paraphernalia may need to be financed, or group excursions and membership fees may be charged. Furthermore, if young people are not able to reach the venue on their own, they have to rely on public transportation or adults to organise the transfer. Here, families with monetary or time constraints are yet again at a disadvantage. But it is particularly the motivation to participate in cultural education that is significantly affected by social strata. The most prominent studies regarding cultural participation come from the field of lifestyle research, which usually draws on the aforementioned Bourdieusian approach that people with higher social status on average are more likely to participate in cultural and arts activities. Though we do not solely look at the traditional high vs. lowbrow divide, our definition of NCE includes variables of both categories. Research shows that variables such as gender (Bennett et al., 2013; Christin, 2012; Coulangeon, 2013), education (Frey \& Meier, 2003), income (Davies, 2005; Hooper-Greenhill, 1994; Katz-Gerro, 2011) and employment (Katz-Gerro, 2002) are very closely linked to cultural participation. Overall, there is a broad consensus in the research literature about the direction of the influence of socioeconomic and demographic characteristics on the decision to visit highbrow cultural institutions in particular, as well as on the frequency of these visits (Falk \& Katz-Gerro, 2016). People in a higher social position are thus more likely to participate in highbrow culture and these lifestyles are again passed on within families to the next generations through socialisation and education (Blossfeld \& Shavit, 2015; Ecarius et al., 2009). Men, people with higher education, more income and more prestigious occupations are therefore more likely to participate in highbrow cultural activities. Following 
the expectation that more resourceful individuals are more likely to participate in non-formal education in general and against an understanding of NCE which includes traditional high-cultural aspects, the third hypothesis is derived:

H3: Individuals with parents with higher social status are more likely to participate in NCE than individuals with parents with lower social status.

We expect that NCE programmes are subject to mechanisms of self-selection as well as mechanisms of socialisation. Certain variables promote participation in NCE programmes, while simultaneously the programmes themselves encourage discussions and critical thinking. Active membership in voluntary associations has often been associated with political engagement, as it provides human and social capital and also promotes soft skills (Bekkers, 2005) and the development of democratic values (Bekkers, 2005; Hooghe, 2003). NCE could build on these benefits and, in addition, promote awareness of plurality and critical reflection through its own mechanisms.

\section{Data and Operationalisation}

We use data from the German National Educational Panel Study (NEPS) to test our hypotheses (Blossfeld et al., 2011). The NEPS is carried out by the LeibnizInstitute for Educational Trajectories at the University of Bamberg. The panel study covers data on educational processes and developments, such as educational decisions, returns to education, different contexts of education and specific competencies. The NEPS monitors six cohorts from birth to old age. Since 2010, nine waves have been collected within this framework. As not all necessary variables are included in all waves, we have decided to conduct cross-sectional analyses using the eighth wave (2016-2017) of the third cohort of the NEPS. Target persons were all children at regular or specialneeds secondary schools in eleventh grade as well as individuals that left school after grades 9 and 10 (NEPS, 2020; Skopek et al., 2012).

The indicator for participation in NCE is constructed using information on cultural club attendance and extracurricular courses. For the former, we included data on club attendance, such as theatre group, youth orchestra, club cultivating local history, folklore club, etc.; responses were (1) yes or (0) no. For extracurricular courses we used information on course attendance outside school in this or the previous school year (excluding sports): If so, what exactly did they do (classes in music schools, classes at Volkshochschule, classes at youth art school); responses were (1) yes or (0) no. Additionally, participants were able to fill in open answers on what specific classes they attended and if they attended any other courses in the past year. All of the open answers are categorized as cultural or non-cultural courses using a pre-designed scheme based on our definition of cultural education. We include all courses in the arts and culture such as pottery classes, piano lessons and synthesizer or woodcraft tutorials without a direct association with economic performance (e.g., German language classes). Individuals who participated in any cultural clubs or courses are coded 1 , if they did not, they are coded 0 .

We further propose to operationalise Adorno's understanding of resistance in terms of protest participation. Therefore, political engagement is measured using potential participation in authorised political demonstrations, as it captures the willingness to "resist" and advocate a certain issue. Contrary to actual protest participation, however, it is not subject to as many external factors such as time, place, individual circumstances and issues (Jenkins et al., 2008, p. 13). The participants were asked whether they could imagine themselves participating (again) in an authorized demonstration on a four-point scale ([1] no, in no way, [2] rather not, [3] rather yes, [4] yes, in any case). We also include two potential mediators of political engagement in the analysis, namely political interest (question: How interested are you in politics? Reponses ranged from [1] not at all interested to [4] very interested) and political discussions (question: When you meet with friends, how often do you discuss political issues? Reponses ranged from [1] never to [5] very often).

The models are fitted based on identified confounding variables. Therefore, variables are added to the model when previous research and literature indicate that both dependent and independent variables are affected. Based on previous studies, we include gender ([0] male, [1] female), household size, highest schoolleaving qualification or current type of school ([0] other, [1] lower secondary, [2] intermediate secondary, and [3] upper secondary education) and immigration status ([0] no/other, [1] first or second-generation) into our analyses. As there is no reliable data on income available, we also add the Comparative Analysis of Social Mobility in Industrial Nations (CASMIN; for more information see Zielonka \& Pelz, 2015) of parents to our analyses representative for socioeconomic status. We additionally include a variable indicating the type of residential area and approximate density of cultural programmes with (0) centre and (1) periphery. The final sample contains 2255 observations. Exclusion from the final sample is mostly due to missing information on the parents' highest CASMIN-Status, as interviews with parents were not always feasible during data collection.

\section{Analysis}

Our analysis is divided into two parts. First, we apply a mediation analysis (Urban \& Mayerl, 2007) based on a successive ordered logistic regression analysis. To identify mediators, we conduct bivariate regression analyses to test the relationships between the independent variable and the mediators, the mediators and the 
dependent variable, as well as between the independent variable and the dependent variable. If the coefficients show significant results that display the expected direction of the effect, the variables are included in the analysis as potential mediators. We then run successive ordered logistic regression models to investigate changes in the effect of cultural education on potential protest participation depending on the mediators. If there is a mediating effect, we expect the coefficient of the independent variable to decrease or disappear $(\mathrm{H} 1 \mathrm{a}, \mathrm{H} 1 \mathrm{~b}$, $\mathrm{H} 2$ ). In a second step, and based on the same sample, we investigate patterns of participation in NCE. Therefore, we run a simple logistic regression model on NCE including important socioeconomic covariates. In doing so, we can roughly outline who participates in non-formal education programmes and who rather does not $(\mathrm{H} 3)$.

\subsection{Mediation Analysis}

The bivariate regression analyses (Table 1 ) show the expected associations between mediators (M), independent variables (I) and dependent variables (D). If individuals participate in cultural education, they are more likely to show higher degrees of political engagement in terms of potential protest participation, political interest and political discussions with friends. Individuals who are more interested in politics and discuss politics more often are on average more likely to potentially participate in political protest. Therefore, we expect to find mediating mechanisms in the data.

In the case of the ordered logistic regression analyses, the data must meet the proportional odds assumption. Using a Brant-Test $\left(\mathrm{Chi}^{2}=31.97 ; \mathrm{p}=0.194\right)$, we confirm that all variables meet the assumption. We estimate three separate successive simple ordered logistic regression models, a bivariate model (OM1), a model including all covariates (OM2) and a model including all covariates as well as the two mediating variables (OM3). Table 2 shows the results of these analyses.

Even though the independent variable shows a strong and significant effect across all models, the coefficient is reduced once the covariates are added and once again when the mediating variables are introduced to the model. The final model (OM3) demonstrates that individuals who participated in NCE are on average 1.2 times more likely to show higher values in potential political protest (ceteris paribus). Furthermore, holding all other variables constant, females and individuals with parents in higher CASMIN categories are on average more likely to report higher values in potential protest participation. Notably, one's educational attainment or current school type shows no consistent and significant influence on potential protest participation. The reason could be that parental education and participation in NCE programmes cancel out the effect of individual education. The moderators, however, exert the strongest effect on potential protest participation. Very politically interested individuals are almost eight times more likely to report higher values in potential protest participation than individuals with no interest at all. Though this result is expectable, we also see that there is a strong increase in effect size between even the lower categories of political interest. Hardly interested individuals are still twice as likely to show higher values on the dependent variable than individuals without any interest. Similarly, the more often individuals have discussions about politics, the more likely they are to show higher values in potential political protest (ceteris paribus).

Figure 1 illustrates the results of OM3. The predicted probabilities on the $\mathrm{Y}$-axis range from 0 to 1 and refer to individuals who have not attended NCE programmes (no) on the left and to those who have participated in these programmes (yes) on the right. The dashed or solid lines represent one of the four categories of the dependent variable as noted in the legend below the graph. Individuals are less likely to indicate that they would not $(0.15)$ or rather not participate $(0.38)$ in authorized demonstrations if they participated in any type of cultural education than their peers $(0.18$ or 0.40$)$. On the other hand, the figure also shows a slight increase in predicted probabilities of protest participation amongst the (rather) approving population if they participated in cultural education (0.27 vs. 0.29). Overall, the predicted probability of (rather) not participating in political protest is lower for individuals that participated in cultural education, while the probability of (rather) participating in political protest is higher.

\subsection{Logistic Regression Analysis}

Based on the same sample, the logistic regression analysis (Table 3 ) shows that, in line with current research on the topic, socioeconomic factors such as the parent's highest CASMIN status and the individual's type

Table 1. Bivariate correlations between the dependent variable, independent variable and mediators.

\begin{tabular}{|c|c|c|c|}
\hline & \multicolumn{3}{|c|}{ Dependent Variables } \\
\hline & Potential Protest Part. (D) & Pol. Interest (M) & Pol. Discussions (M) \\
\hline NCE (I) & $+* * *(1)$ & $+* * *(1)$ & $+* * *(2)$ \\
\hline Political Interest (M) & $+* * *(1)$ & . & . \\
\hline Political Discussions (M) & $+* * *(1)$ & . & . \\
\hline
\end{tabular}

Notes: (1) Ordered logistic regression, (2) linear regression; ${ }^{*} p<0.05,{ }^{* *} p<0.01,{ }^{* * *} p<0.001$. 
Table 2. Ordered logistic regressions on potential protest participation.

\begin{tabular}{|c|c|c|c|c|c|c|}
\hline & OM1 & OM1 (OR) & OM2 & $\mathrm{OM} 2$ (OR) & OM3 & OM3 (OR) \\
\hline NCE (ref. No) & $\begin{array}{l}0.440 * * * \\
(0.087)\end{array}$ & $1.553^{* * *}$ & $\begin{array}{l}0.281^{* *} \\
(0.091)\end{array}$ & $1.324 * *$ & $\begin{array}{c}0.188^{*} \\
(0.093)\end{array}$ & $1.206^{*}$ \\
\hline Female (ref. Male) & & & $\begin{array}{c}0.229 * * \\
(0.078)\end{array}$ & $1.257^{* *}$ & $\begin{array}{l}0.481 * * * \\
(0.081)\end{array}$ & $1.618^{* * *}$ \\
\hline \multicolumn{7}{|c|}{ Secondary Education (ref. Upper) } \\
\hline Other & & & $\begin{array}{c}0.459 * * \\
(0.164)\end{array}$ & $1.582 * *$ & $\begin{array}{l}0.544^{* *} \\
(0.167)\end{array}$ & $1.723^{* *}$ \\
\hline Lower Secondary & & & $\begin{array}{c}-0.362 \\
(0.199)\end{array}$ & 0.696 & $\begin{array}{c}0.073 \\
(0.202)\end{array}$ & 1.076 \\
\hline Intermediate Secondary & & & $\begin{array}{c}-0.181 \\
(0.093)\end{array}$ & 0.835 & $\begin{array}{c}0.032 \\
(0.095)\end{array}$ & 1.033 \\
\hline CASMIN & & & $\begin{array}{l}0.130 * * * \\
(0.022)\end{array}$ & $1.139 * * *$ & $\begin{array}{l}0.107^{* * *} \\
(0.023)\end{array}$ & $1.113^{* * *}$ \\
\hline Imm. Status (ref. No) & & & $\begin{array}{c}0.101 \\
(0.146)\end{array}$ & 1.106 & $\begin{array}{c}0.093 \\
(0.149)\end{array}$ & 1.098 \\
\hline Household Size & & & $\begin{array}{c}-0.026 \\
(0.027)\end{array}$ & 0.975 & $\begin{array}{c}0.004 \\
(0.028)\end{array}$ & 1.004 \\
\hline Periphery (ref. Centre) & & & $\begin{array}{c}-0.203^{*} \\
(0.0897)\end{array}$ & $0.816^{*}$ & $\begin{array}{l}-0.149 \\
(0.0912)\end{array}$ & 0.861 \\
\hline Political Discussions & & & & & $\begin{array}{c}0.441 * * * \\
(0.0526)\end{array}$ & $1.555^{* * *}$ \\
\hline \multicolumn{7}{|c|}{ Political Interest (ref. Not at All) } \\
\hline Hardly & & & & & $\begin{array}{l}0.665^{* * *} \\
(0.169)\end{array}$ & $1.945^{* * *}$ \\
\hline Fairly & & & & & $\begin{array}{l}1.223^{* * *} \\
(0.180)\end{array}$ & $3.397^{* * *}$ \\
\hline Very Interested & & & & & $\begin{array}{l}2.035^{* * *} \\
(0.210)\end{array}$ & $7.654^{* * *}$ \\
\hline \multicolumn{7}{|l|}{ I } \\
\hline cut1 & $\begin{array}{l}-1.476 * * * \\
(0.0594)\end{array}$ & $0.229 * * *$ & $\begin{array}{l}-0.933 * * * \\
(0.200)\end{array}$ & $0.393 * * *$ & $\begin{array}{l}1.232^{* * *} \\
(0.274)\end{array}$ & $3.428 * * *$ \\
\hline cut2 & $\begin{array}{c}0.381 * * * \\
(0.0488)\end{array}$ & $1.463 * * *$ & $\begin{array}{l}0.981^{* * *} \\
(0.200)\end{array}$ & $2.668 * * *$ & $\begin{array}{l}3.352 * * * \\
(0.283)\end{array}$ & $28.550 * * *$ \\
\hline cut3 & $\begin{array}{l}1.791 * * * \\
(0.0636)\end{array}$ & $5.997 * * *$ & $\begin{array}{l}2.429 * * * \\
(0.205)\end{array}$ & $11.340 * * *$ & $\begin{array}{l}4.975^{* * *} \\
(0.291)\end{array}$ & $144.700 * * *$ \\
\hline Observations & 2255 & 2255 & 2255 & 2255 & 2255 & 2255 \\
\hline Pseudo $\mathrm{R}^{2}$ & 0.004 & 0.004 & 0.02 & 0.02 & 0.081 & 0.081 \\
\hline
\end{tabular}

Notes: Standard errors in parentheses; ${ }^{*} p<0.05,{ }^{* *} p<0.01,{ }^{* * *} p<0.001$ 


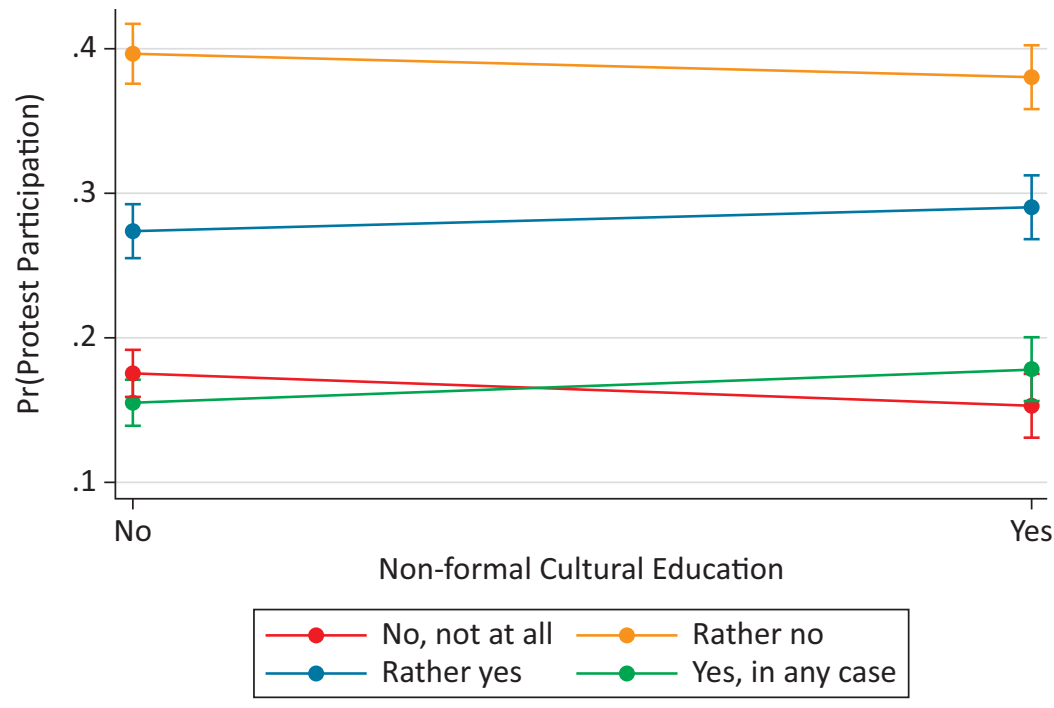

Figure 1. Predicted probabilities (predictive margins with $95 \% \mathrm{Cls}$ ) for potential protest participation by NCE.

Table 3. Logistic regressions on NCE.

\begin{tabular}{|c|c|c|c|c|}
\hline & LM1 & LM1 (OR) & LM2 & LM2 (OR) \\
\hline \multicolumn{5}{|c|}{ Secondary Education (ref. Upper) } \\
\hline Other & $\begin{array}{c}-0.483^{*} \\
(0.212)\end{array}$ & $0.617^{*}$ & $\begin{array}{c}-0.468^{*} \\
(0.215)\end{array}$ & $0.626^{*}$ \\
\hline Lower & $\begin{array}{l}-1.552 * * * \\
(0.379)\end{array}$ & $0.212^{* * *}$ & $\begin{array}{l}-1.539 * * * \\
(0.383)\end{array}$ & $0.215^{* * *}$ \\
\hline Intermediate & $\begin{array}{l}-0.971^{* * *} \\
(0.126)\end{array}$ & $0.379 * * *$ & $\begin{array}{l}-0.971 * * * \\
(0.129)\end{array}$ & $0.379 * * *$ \\
\hline CASMIN & $\begin{array}{c}0.138 * * * \\
(0.0282)\end{array}$ & $1.148 * * *$ & $\begin{array}{c}0.144^{* * * *} \\
(0.0293)\end{array}$ & $1.155^{* * *}$ \\
\hline Female (ref. Male) & & & $\begin{array}{l}0.612^{* * *} \\
(0.101)\end{array}$ & $1.843^{* * *}$ \\
\hline Immigration Status (ref. No) & & & $\begin{array}{c}-0.127 \\
(0.195)\end{array}$ & 0.881 \\
\hline Household Size & & & $\begin{array}{c}0.131^{* * *} \\
(0.0346)\end{array}$ & $1.140 * * *$ \\
\hline Periphery (ref. Centre) & & & $\begin{array}{c}0.199 \\
(0.116)\end{array}$ & 1.221 \\
\hline Constant & $\begin{array}{l}-1.489 * * * \\
(0.189)\end{array}$ & $0.226 * * *$ & $\begin{array}{l}-2.507^{* * *} \\
(0.268)\end{array}$ & $0.082 * * *$ \\
\hline Observations & 2255 & & 2255 & \\
\hline Pseudo $\mathrm{R}^{2}$ & 0.06 & & 0.08 & \\
\hline
\end{tabular}

Notes: Standard errors in parentheses; ${ }^{*} p<0.05,{ }^{* *} p<0.01,{ }^{* * *} p<0.001$.

of education are very important when looking at NCE participation. The individual's educational background alone accounts for approximately $6 \%$ of the unexplained variance in the dependent variable. In model 2 , individuals in upper secondary education are on average $(1 / \exp (-0.971)=2.64)$ almost three times more likely to participate in NCE than individuals in intermediate secondary education and almost five $(1 / \exp (-1.552)=4.72)$ times more likely than individuals from lower secondary education ceteris paribus. Interestingly, immigration status and centrality of the area of residence do not significantly affect participation in NCE programmes. Contrary 
to similar studies, an increasing household size does not prohibit extracurricular participation but fosters it.

Figure 2 illustrates the increasing predicted probabilities of participating in NCE by parental CASMIN status and individual education based on LM2 while holding all other variables at their means. Overall, individuals across all types of schools are more likely to participate in NCE when their parents' CASMIN status increases. Not only are individuals with higher education more likely to participate in NCE when their parents' CASMIN status increases, but they also show higher intercepts.

\section{Discussion and Conclusion}

In this article, we aimed to take a closer look at the politicised topic of the acclaimed effects of cultural education and to draw conclusions about measurable consequences. The study focused on the politicalemancipatory outcomes of NCE. In a two-part analysis, we first examined the indirect and direct effects of NCE on potential protest participation. Second, we investigated the extent to which participation in NCE programmes is limited by an individual's socioeconomic and regional background. This study drew on the theoretical aspects of two of the most prominent theorists on the function of culture and arts in society: Theodor Adorno and Pierre Bourdieu. Even if our data cannot exactly reflect both theories, this work makes a fruitful first attempt to empirically combine theoretical facets of both approaches. While previous studies in the fields of education and culture have often relied on concepts of one of the two theorists, we show that a combination might avoid the dichotomisation of highbrow and lowbrow activities and promote the discovery of previously unknown patterns of participation. In this way, our article also contributes to the diversification of theory-based empirical research in the field of cultural education.
Based on NEPS data, we conducted a mediation analysis using successive ordered logistic regression models. Our results indicated that both political discussions ( $\mathrm{H} 1 \mathrm{a})$ and political interest ( $\mathrm{H} 1 \mathrm{~b})$ mediate the effect of participation in NCE on potential protest participation, while not accounting for the total effect of NCE participation on the dependent variable $(\mathrm{H} 2)$. Our logistic regression analyses further suggested that individuals with parents with higher social status are more likely to participate in NCE than individuals with lower social status (H3). The results of the analyses of NCE were consistent with results from previous research on participation in cultural activities (Notten et al., 2015). Individuals in upper secondary education and/or with parents in higher CASMIN categories were significantly more likely to participate in NCE than individuals in lower secondary education and/or with parents in lower CASMIN categories. While all individuals were more likely to participate, when their parents are in higher CASMIN categories, upper secondary individuals profit most from their parents' status. Though we included only a few variables, they explained NCE participation to a relatively large degree. Overall, the estimations supported all of our hypotheses. These findings tie in very well with our theoretical considerations, but also underline the challenges of cultural education programmes and their impact. We see that access to culture is not yet sufficiently developed and that the diversity Bourdieu later emphasised is not yet fully achieved. However, we also recognize that sociodemographic and socioeconomic factors do not solely determine access and participation. Many other variables also influence participation. Presumably, promoting access and participation opportunities and diversifying participants in arts education is only realistic if lower-threshold programmes are created (Bourdieu \& Haacke, 1995). Participation in cultural education programmes is linked to knowledge or awareness of programmes by the (potential) participants as participation only takes place when people

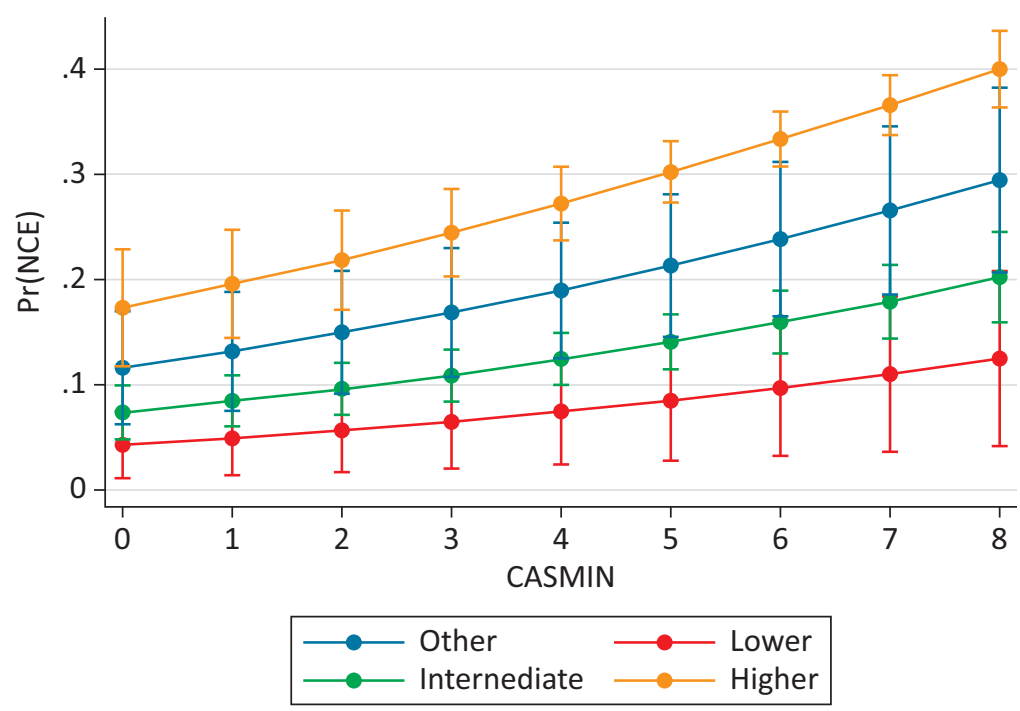

Figure 2. Predicted probabilities of participation in NCE with $95 \% \mathrm{Cls}$ by secondary education and CASMIN. 
are willing to participate. Following Bourdieu's considerations, it can also be assumed that political participation (e.g., in the sense of demonstrations or potential participation in demonstrations) is subject to discriminatory mechanisms (Bourdieu, 1981, 2000; Harrits, 2011). Every barrier to participation, therefore, acts in addition to and concerning all other barriers and does not stand alone.

The findings presented in this article offer new, empirical insights into the often-proclaimed association between cultural education and political engagement. The analyses illustrated that NCE adds a small but significant factor to potential protest participation. This difference in NCE participation may just determine whether individuals participate in demonstrations. Our study also shows that participation in NCE exerts a direct effect on potential protest participation that is not accounted for by the variables in the model. Unfortunately, due to patchy and relatively superficial data in the area of cultural education, we can only speculate about the nature of the direct effect. One plausible possibility would be that the effect can be explained by unidentified or unmeasured mediating variables, such as personality traits or soft skills. Concepts such as critical thinking competencies or self-efficacy were not available in the data and therefore not included in the models. Similarly, we have no information on the specific content or didactic of the NCE programme. We therefore cannot specify how the content was presented in the NCE programmes. Programmes in Volkshochschulen (education centres) in particular are often delivered in relatively closed formats and therefore do not necessarily offer space for open discussions or alternative methods of learning. Nonetheless, non-formal education offers the advantages for cultural education that it is mostly free of performance pressure, largely non-instrumental and does not have to follow the strict structure and rhythm of most formal educational programmes.

The aim of the present study was not to explain (potential) protest participation (Skoric et al., 2016; Theocharis \& van Deth, 2018) nor participation in cultural education (Notten et al., 2015) in total, as both concepts have been thoroughly investigated before. We did, instead, empirically demonstrate the links between both concepts. To identify causal relations between cultural education and political engagement, longitudinal data would be needed. Further research should therefore develop appropriate and comprehensive models to better understand the association between cultural education and political engagement. For this purpose, data that contain all the necessary information must be compiled, collected and prepared. At the same time, it is important to look at cultural education in an interdisciplinary and multidimensional way to be able to precisely understand the mechanisms. However, more data are needed to conduct such differentiated studies that take into account the different mechanisms.

Is cultural education a panacea for social cohesion and democratic structures? Our analysis shows that NCE at least contributes to fostering democratic behaviour and skills. At the same time, participation in non-formal education is highly selective and along social strata, not all people show the same likelihood to participate. Even though participation in NCE promotes certain aspects of democratic thinking, not all individuals have access to these programmes. NCE programmes therefore primarily reach and empower people who are already on average better situated and educated. Even if our analyses show no direct effects or inconclusive results on the effects of formal education on potential protest participation, formal education still exerts a significant effect on participation in NCE, which in return then affects political interest, political discussions and protest participation. In conclusion, NCE provides important tools to support democratic structures and addresses many of the current social problems. Participation in NCE, however, is highly selective. If these inequalities cannot be eliminated or addressed, then the benefits of NCE cannot be distributed equally across society and inequalities might be amplified.

\section{Acknowledgments}

The study was funded by the Federal Ministry of Education and Research under the MetaKLuB research project Kulturelle Bildung in ländlichen Räumen ("Cultural Education in Rural Areas"; research grant number 01JKL19MET). We also thank the publication fund made available by Freie Universität Berlin to cover the article processing charges associated with this publication. This article uses data from the German National Educational Panel Study collected from 2008 to 2013 as part of the "Framework Programme for the Promotion of Empirical Educational Research," which was funded by the Federal Ministry of Education and Research. Since 2014, the NEPS has been conducted by the Leibniz Institute for Educational Trajectories e.V. (LIfBi) at the Otto Friedrich University of Bamberg in cooperation with a Germany-wide network.

\section{Conflict of Interests}

The authors declare no conflict of interests.

\section{References}

Adorno, T. W., \& Ashton, E. B. (2007). Negative dialectics. Continuum.

Almond, G. A., \& Verba, S. (2015). The civic culture: Political attitudes and democracy in five nations. Princeton University Press. http://www.jstor.org/stable/ j.ctt183pnr2 https://doi.org/10.2307/j.ctt183pnr2

Baggetta, M. (2009). Civic opportunities in associations: Interpersonal interaction, governance experience and institutional relationships. Social Forces, 88(1), 175-199. https://doi.org/10.1353/sof.0.0231

Bekkers, R. (2005). Participation in voluntary associ- 
ations: Relations with resources, personality, and political values. Political Psychology, 26(3), 439-454. https://doi.org/10.1111/j.1467-9221.2005.00425.x

Bennett, T., Bustamante, M., \& Frow, J. (2013). The Australian space of lifestyles in comparative perspective. Journal of Sociology, 49, 224-255. https://doi.org/ $10.1177 / 1440783313481523$

Blossfeld, H.-P., \& Shavit, Y. (2015). Persisting barriers: Changes in educational opportunities in thirteen countries. In R. Arum, I. r. Beattle, \& K. Ford (Eds.), The structure of schooling: Readings in the sociology of education. (3rd ed., pp. 274-287). SAGE.

Blossfeld, H.-P., Roßbach, H.-G., \& von Maurice, J. (Eds.). (2011). Education as a lifelong process-The German National Educational Panel Study (NEPS). Springer.

Blossfeld, P. N., Blossfeld, G. J., \& Blossfeld, H.-P. (2015). Educational expansion and inequalities in educational opportunity: Long-term changes for East and West Germany. American Journal of Sociology, 31(2), 144-160. https://doi.org/10.1093/esr/jcv017

Bock-Famulla, K., Lange, J., \& Strunz, E. (2015). Länderreport Frühkindliche Bildungssysteme 2015: Transparenz schaffen; Governance stärken [State report early childhood education systems 2015: Creating transparency; strengthening governance]. Bertelsmann Stiftung.

Bockhorst, H. (2008). Kulturelle Bildung-Schlüssel für Lebenskunst und Teilhabe: Konzeptionelle Grundlagen und Strategien in der BKJ [Cultural educationKey to the art of living and participation: Conceptual principles and strategies in the BKJ]. In J. Maedler (Ed.), Kulturelle Bildung: Vol. 4. TeilHabeNichtse: Chancengerechtigkeit und kulturelle Bildung [Cultural education: Vol. 4. Equal opportunities and cultural education] (1st ed., pp. 78-101). kopaed.

Boudon, R. (1974). Education, opportunity, and social inequality: Changing prospects in Western society. Wiley.

Bourdieu, P. (1981). Eine illegitime Kunst: die sozialen Gebrauchsweisen der Photographie [An illegitimate art: The social uses of photography]. Europäische Verlagsanstalt.

Bourdieu, P. (1984). Distinction: A social critique of the judgement of taste. Harvard University Press.

Bourdieu, P. (1998). Practical reason: On the theory of action. Stanford University Press.

Bourdieu, P. (2000). Pascalian meditations. Stanford University Press.

Bourdieu, P., \& Haacke, H. (1995). Free exchange. Stanford University Press.

Brähler, E., Decker, O., \& Kiess, J. (Eds.). (2016). Forschung Psychosozial. Die enthemmte Mitte: Autoritäre und rechtsextreme Einstellung in Deutschland: die Leipziger "Mitte"-Studie 2016 [Psychosocial research. The disinhibited middle: Authoritarian and far-right attitudes in Germany: The Leipzig "Mitte" study 2016]. Psychosozial-Verlag.

Christin, A. (2012). Gender and highbrow cultural partic- ipation in the United States. Poetics, 40(5), 423-443. https://doi.org/10.1016/J.POETIC.2012.07.003

Coulangeon, P. (2013). Changing policies, challenging theories and persisting inequalities: Social disparities in cultural participation in France from 1981 to 2008. Poetics, 41(2), 177-209. https://doi.org/10.1016/ J.POETIC.2012.12.003

Davies, S. (2005). Still popular: Museums and their visitors 1994-2004. Cultural Trends, 14(1), 67-105. https://doi.org/10.1080/09548960500164509

de Tocqueville, A. (1969). Democracy in America. Anchor books; Doubleday.

Desjardins, R., \& Schuller, T. (2006). Measuring the effects of education on health and civic engagement: Proceedings of the Copenhagen Symposium. Copenhagen.

Dumitru, D. (2019). Creating meaning. The importance of arts, humanities and culture for critical thinking development. Studies in Higher Education, 44(5), 870-879. https://doi.org/10.1080/03075079. 2019.1586345

Ecarius, J., Groppe, C., \& Malmede, H. (2009). Familie und öffentliche Erziehung: Theoretische Konzeptionen, historische und aktuelle Analysen [Family and public education: Theoretical conceptions, historical and current analyses]. Springer.

Falk, M., \& Katz-Gerro, T. (2016). Cultural participation in Europe: Can we identify common determinants? Journal of Cultural Economics, 40(2), 127-162. https://doi.org/10.1007/S10824-015-9242-9

Fietz, Y. (2009, September 30). Partizipation durch Kultur [Participation through Culture]. Dossier Kulturelle Bildung. https://www.bpb.de/gesellschaft/ bildung/kulturelle-bildung/59951/partizipationdurch-kultur?p=all

Frey, B. S., \& Meier, S. (2003). The economics of museums (Working Paper No. 149). Institute for Empirical Economic Research. http://dx.doi.org/10.2139/ ssrn.413901

Fuchs, M. (2008). Kultur Macht Sinn [Culture makes sense]. Springer. https://doi.org/10.1007/978-3531-91164-9

Gartman, D. (2012). Bourdieu and Adorno: Converging theories of culture and inequality. Theory and Society, 41(1), 41-72. https://doi.org/10.1007/s11186011-9159-z

Grotlüschen, A. (2016). Politische GrundbildungTheoretische und empirische Annäherungen [Basic political education-Theoretical and empirical approaches]. Zeitschrift für Weiterbildungsforschung, 39(2), 183-203.

Guiller, J., Durndell, A., \& Ross, A. (2008). Peer interaction and critical thinking: Face-to-face or online discussion? Learning and Instruction, 18(2), 187-200. https://doi.org/10.1016/j.learninstruc.2007.03.001

Harrits, G. S. (2011). Political power as symbolic capital and symbolic violence. Journal of Political Power, 4(2), 237-258. https://doi.org/10.1080/2158379X. 
2011.589178

Holtmann, E. (2020). Deutschland 2020: Unheilbar gespalten? [Germany 2020: Incurably divided?]. Zeitschrift für Politikwissenschaft, 30, 1-7. https:// doi.org/10.1007/s41358-020-00223-6

Holtmann, E., Brachert, M., \& Gabriel, O. W. (2019). Die Umdeutung der Demokratie: Politische Partizipation in Ost-und Westdeutschland [The reinterpretation of democracy: Political participation in East and West Germany]. Campus.

Hooghe, M. (2003). Voluntary associations and democratic attitudes: Value congruence as a causal mechanism. In M. Hooghe \& D. Stolle (Eds.), Generating social capital: Civil society and institutions in comparative perspective (pp. 89-111). Macmillan. https:// doi.org/10.1057/9781403979544_5

Hooper-Greenhill, E. (1994). Museums and their visitors. Routledge.

Jenkins, J. C., Wallace, M., \& Fullerton, A. S. (2008). A Social movement society? a cross-national analysis of protest potential. International Journal of Sociology, 38(3), 12-35. https://doi.org/10.2753/IJS00207659380301

Jessop, S. (2017). Adorno: Cultural education and resistance. Studies in Philosophy and Education, 36(4), 409-423. https://doi.org/10.1007/s11217-0169531-6

Katz-Gerro, T. (2002). Highbrow cultural consumption and class distinction in Italy, Israel, West Germany, Sweden, and the United States. Social Forces, 81(1), 207-229. http://www.jstor.org/stable/3086532

Katz-Gerro, T. (2011). Cross-national cultural consumption research: Inspirations and disillusions. In J. Rössel \& G. Otte (Eds.), Lebensstilforschung [Lifestyle research] (pp. 339-360). Springer.

Kolleck, N., \& Büdel, M. (2020). Kulturelle Bildung in ländlichen Räumen: Vorstellung der Forschungsvorhaben der BMBF-Förderrichtlinie [Cultural education in rural areas: Introduction to the research projects of the BMBF Funding Guideline]. Kulturelle Bildung Online. https://doi.org/10.25529/92552.558

Lampert, N. (2006). Critical thinking dispositions as an outcome of art education. Studies in Art Education, 47(3), 215-228. https://doi.org/10.1080/00393541. 2006.11650083

Liebau, E. (2018). Kulturelle und Ästhetische Bildung [Cultural and aesthetic education]. In R. Tippelt \& B. Schmidt-Hertha (Eds.), Handbuch Bildungsforschung [Handbook of educational research] (pp. 1219-1239). Springer. https://doi.org/10.1007/9783-531-19981-8_54

Maaz, K., Baumert, J., \& Trautwein, U. (2010). Genese sozialer Ungleichheit im institutionellen Kontext der Schule: Wo entsteht und vergrößert sich soziale Ungleichheit? [Genesis of social inequality in the institutional context of school: Where does social inequality arise and increase?]. In H.-H. Krüger, U. Rabe-Kleberg, R.-T. Kramer, \& J. Budde (Eds.), Studien zur Schul- und Bildungsforschung: Vol. 30. Bildungsungleichheit revisited: Bildung und soziale Ungleichheit vom Kindergarten bis zur Hochschule [Studies in school and educational research: Vol. 30. Educational inequality revisited: Education and social inequality from kindergarten to higher education] (1st ed., pp. 69-102). Springer. https://doi.org/10.1007/9783-531-92201-0_5

Müller, S. (2019). Vereintes Land-Drei Jahrzehnte nach dem Mauerfall [United country-Three decades after the fall of the Wall]. IWH Halle Institute for Economic Research.

National Educational Panel Study. (2020). Study overview: NEPS starting cohort 3-Grade 5: Paths through lower secondary school-Educational pathways of students in grade 5 and higher (Waves 1 to 10). Leibniz Institute for Educational Trajectories.

Notten, N., Lancee, B., van de Werfhorst, H. G., \& Ganzeboom, H. B. G. (2015). Educational stratification in cultural participation: Cognitive competence or status motivation? Journal of Cultural Economics, 39(2), 177-203. https://doi.org/10.1007/ s10824-014-9218-1

Organisation for Economic Co-operation and Development. (2011). Germany: Once weak international standing prompts strong nationwide reforms for rapid improvement. In Strong performers and successful reformers in education (pp. 201-220). https:// doi.org/10.1787/9789264096660-10-en

Oros, A. L. (2007). Let's debate: Active learning encourages student participation and critical thinking. Journal of Political Science Education, 3(3), 293-311. https://doi.org/10.1080/15512160701558273

Putnam, R. D. (2001). Bowling alone: The collapse and revival of American community (1 ed.). Simon \& Schuster.

Quintelier, E. (2013). Socialization or self-selection? Membership in deliberative associations and political attitudes. Nonprofit and Voluntary Sector Quarterly, 42(1), 174-192. https://doi.org/10.1177/ 0899764011434556

Rat für Kulturelle Bildung e.V. (2015). Youth/arts/ experience. Horizon 2015: Study: Cultural understanding, cultural interests and activities of 9th and 10th grade students at general education schools. Encounter opportunities and experiences with the arts. Rat für Kulturelle Bildung e.V.

Rehberg, K.-S. (2006). Ost-West. [East-West]. In S. Lessenich \& F. Nullmeier (Eds.), Deutschland-Eine gespaltene Gesellschaft [Germany-A divided society]. Campus.

Skopek, J., Pink, S., \& Bela, D. (2012). Data manual. Starting cohort 3: From lower to upper secondary school (NEPS SC3 1.0.0). Leibniz Institute for Educational Trajectories.

Skoric, M. M., Zhu, Q., Goh, D., \& Pang, N. (2016). Social media and citizen engagement: A meta-analytic review. New Media \& Society, 18(9), 1817-1839. 
https://doi.org/10.1177/1461444815616221

Szabo, Z., \& Schwartz, J. (2011). Learning methods for teacher education: The use of online discussions to improve critical thinking. Technology, Pedagogy and Education, 20(1), 79-94. https://doi.org/10.1080/ 1475939X.2010.534866

Theocharis, Y., \& van Deth, J. W. (2018). The continuous expansion of citizen participation: A new taxonomy. European Political Science Review, 10(1), 139-163. https://doi.org/10.1017/S1755773916000230

Urban, D., \& Mayerl, J. (2007). Mediator-Effekte in der Regressionsanalyse (direkte, indirekte und totale Effekte) [Mediator effects in regressions analysis-Direct, indirect and total effects]. ResearchGate. https://www.researchgate.net/publication/ 242548002

van der Meer, T. W. G., \& van Ingen, E. J. (2009). Schools of democracy? Disentangling the relationship between civic participation and political action in 17 European countries. European Journal of Political Research, 48(2), 281-308. https://doi.org/ 10.1111/j.1475-6765.2008.00836.x van Deth, J. W. (2000). Interesting but irrelevant: Social capital and the saliency of politics in Western Europe. European Journal of Political Research, 37(2), 115-147. https://doi.org/10.1111/1475-6765. 00507

van Deth, J. W. (2015). What is political participation? In W. R. Thompson (Ed.), Oxford research encyclopedias. https://doi.org/10.1093/acrefore/9780190 228637.013.68

Verba, S., Schlozman, K. L., \& Brady, H. E. (1995). Voice and equality: Civic voluntarism in American politics. Harvard University Press.

von Below, S., Powell, J. J. W., \& Roberts, L. W. (2013). Educational systems and rising inequality. Sociology of Education, 86(4), 362-375. https://doi.org/ $10.1177 / 0038040713496585$

Zielonka, M., \& Pelz, S. (2015). NEPS technical report: Implementation of the ISCED-97, CASMIN and years of education classification schemes in SUF starting cohort 3. Leibniz Institute for Educational Trajectories.

\section{About the Authors}

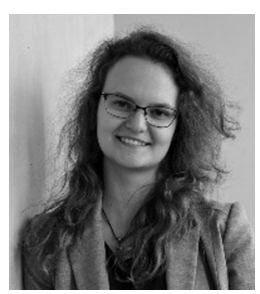

Lea Fobel $(\mathrm{PhD})$ is a Research Fellow the University of Leipzig in the meta-research project "Cultural Education in Rural Areas." Previously, she worked at the Research Institute for Regional and Urban Development in Dortmund after obtaining her Bachelor and Master's degrees in sociology and population studies in Bielefeld, Cologne and Groningen. Her research focuses mainly on spatial inequality research, social participation and empirical, especially quantitative methods. https://orcid.org/00000002-3175-1646

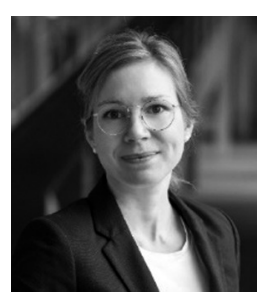

Nina Kolleck is a Professor at Leipzig University and Head of the Institute of Educational Research and Social Systems at Freie Universität Berlin. Previously, she held professorships at RWTH Aachen and FU Berlin as well as visiting professorships at the University of California Berkeley, the University of British Columbia in Vancouver, the Hebrew University of Jerusalem, and Tel Aviv University. She received various awards, including the Award for Research Cooperation and Highest Excellence in Science from the Max Planck Society. https://orcid.org/0000-0002-5499-8617 